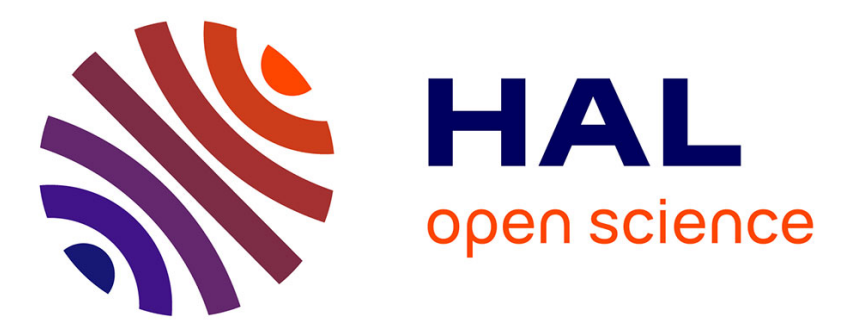

\title{
La dégénérescence du complexe lombo-pelvien influence le risque de luxation de prothèse totale de hanche: étude cas-témoin
}

\author{
Louis Dagneaux, Stanislas Marouby, Cedric Maillot, François Canovas, \\ Charles Rivière
}

\section{To cite this version:}

Louis Dagneaux, Stanislas Marouby, Cedric Maillot, François Canovas, Charles Rivière. La dégénérescence du complexe lombo-pelvien influence le risque de luxation de prothèse totale de hanche: étude cas-témoin. Revue de Chirurgie Orthopédique et Traumatologique, 2019, 105, pp.313 - 319. 10.1016/j.rcot.2018.12.019 . hal-03484736

\section{HAL Id: hal-03484736 \\ https://hal.science/hal-03484736}

Submitted on 20 Dec 2021

HAL is a multi-disciplinary open access archive for the deposit and dissemination of scientific research documents, whether they are published or not. The documents may come from teaching and research institutions in France or abroad, or from public or private research centers.
L'archive ouverte pluridisciplinaire HAL, est destinée au dépôt et à la diffusion de documents scientifiques de niveau recherche, publiés ou non, émanant des établissements d'enseignement et de recherche français ou étrangers, des laboratoires publics ou privés.

\section{()ㅜ(1)}

Distributed under a Creative Commons Attribution - NonCommerciall 4.0 International 
Version of Record: https://www.sciencedirect.com/science/article/pii/S1877051718305677

Manuscript_cf3a7a4bebfbf6b964053a8b6b52e265

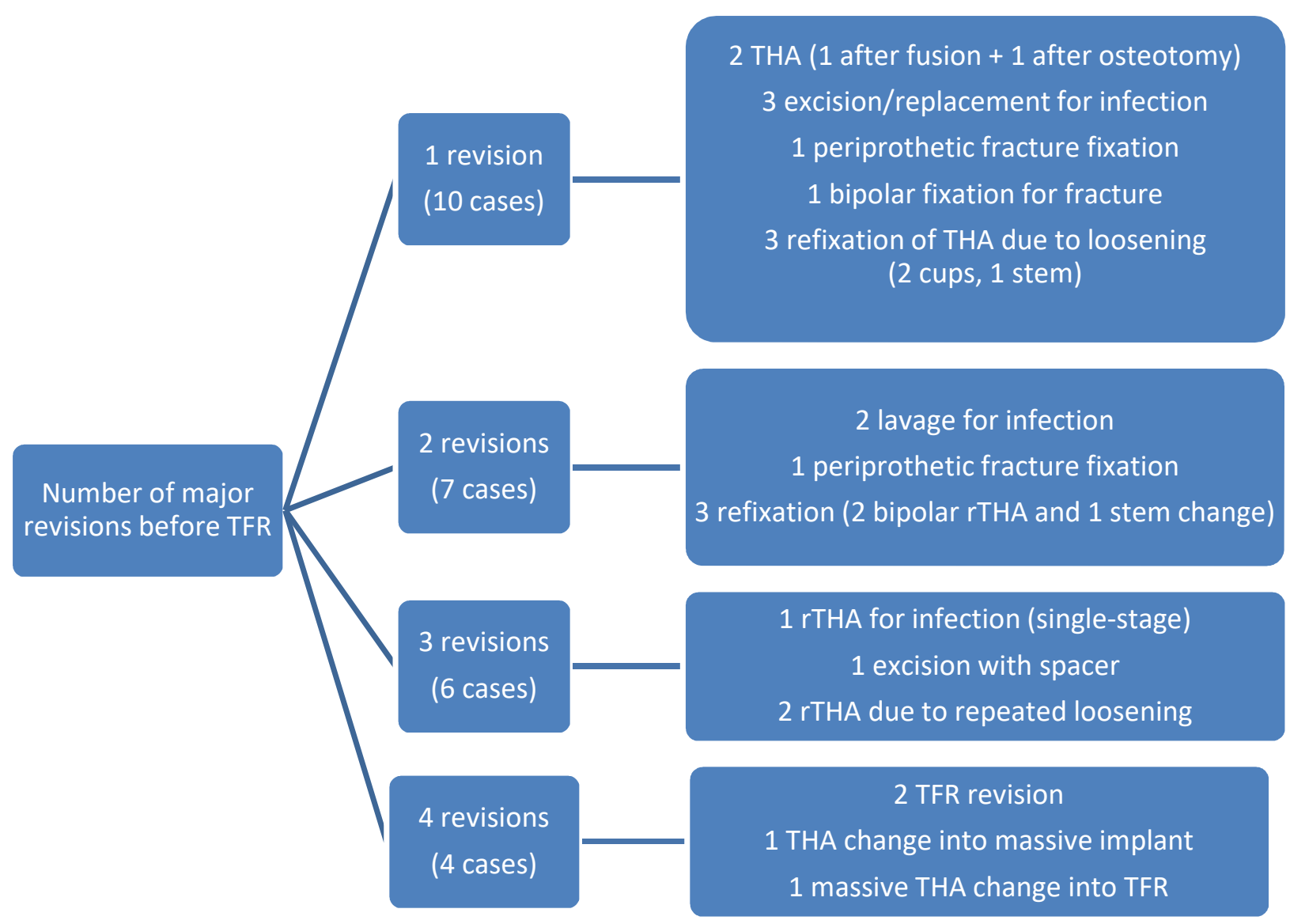

(C) 2018 published by Elsevier. This manuscript is made available under the CC BY NC user license https://creativecommons.org/licenses/by-nc/4.0/ 


\begin{tabular}{|c|}
\hline 1672 PTH primaires \\
Implants conventionnels \\
(base de données entre 2009 et 2017) \\
\hline
\end{tabular}

\section{PTH primaires}

Implants Double-mobilité (base de données entre 2009 et 2017)

\section{0 luxations}

\section{7 patients exclus}

8 instrumentations lombaires

6 démences

4 scores ASA 4

4 contextes de chutes à

répétition

8 cas de révision prothétique

8 erreurs de positionnement des

implants évidentes

19 dossiers incomplets

\section{Group 1:}

33 patients avec $\mathrm{PTH}$ instables Implants conventionnels
1044 PTH stables

Implants Double-mobilité

\section{Group 2:}

41 patients avec $P$ TH stables Implants conventionnels
1052 PTH stables

Implants conventionnels

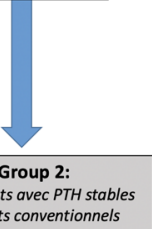

\section{Group 3:}

41 patients avec $\mathrm{PTH}$ stables Implants double-mobilité 


\section{be:}

\section{b.}

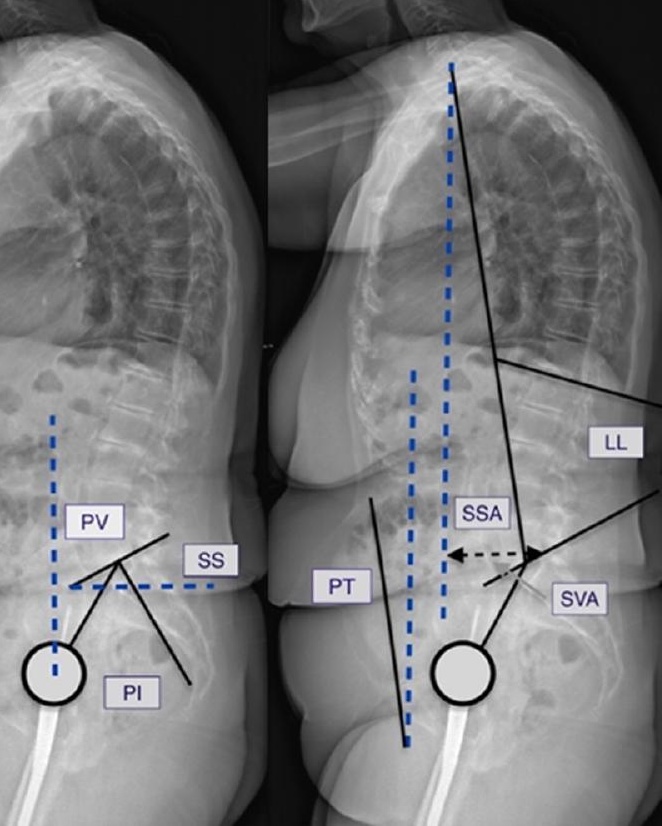




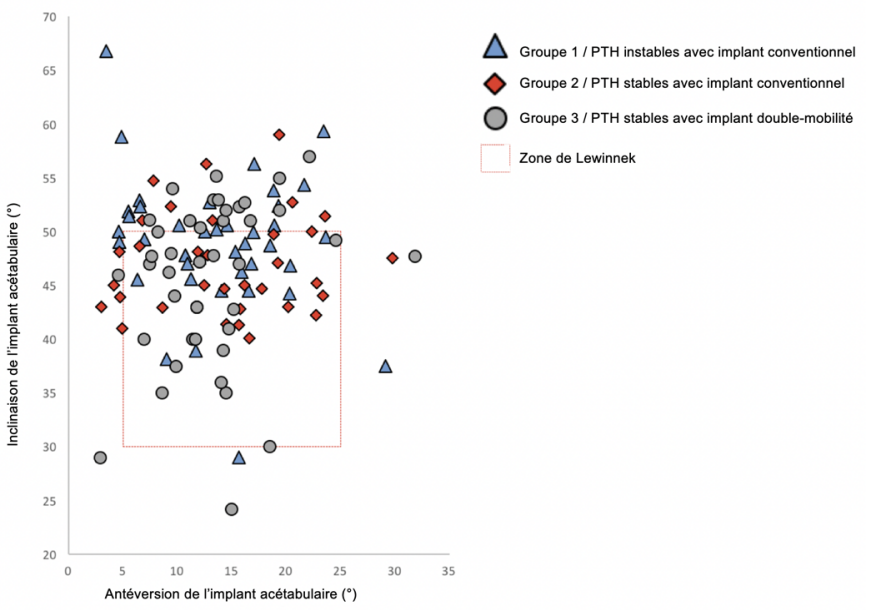


난

مئ

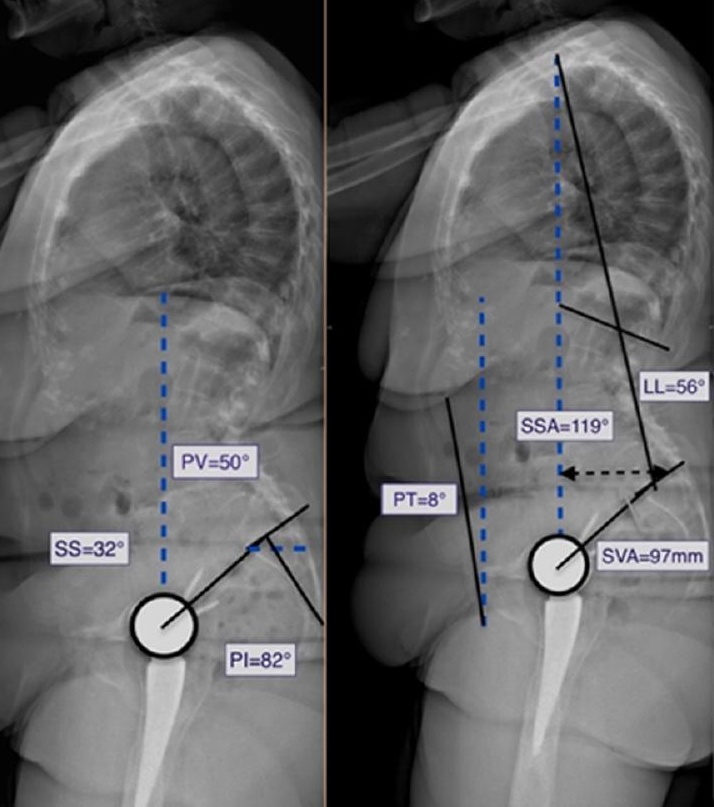

